\title{
FORMULATION AND EVALUATION OF PRONIOSOMAL GEL-BASED TRANSDERMAL DELIVERY OF ATORVASTATIN CALCIUM BY BOX-BEHNKEN DESIGN
}

\author{
SOUJANYA C ${ }^{1 *}$, RAVI PRAKASH P ${ }^{2}$ \\ ${ }^{1}$ Department of Pharmaceutics, Vishnu Institute of Pharmaceutical Education and Research, Narsapur, Telangana, India. ${ }^{2}$ Department of \\ Pharmaceutics, CES College of Pharmacy, Kurnool, Andhra Pradesh, India. Email: sunkusoujanya@gmail.com
}

Received: 16 April 2018, Revised and Accepted: 23 October 2018

\section{ABSTRACT}

Objective: The aim of this study was to investigate the combined influence of three independent variables in the preparation of atorvastatin proniosomes by coacervation-phase separation method.

Methods: On the basis of the preliminary trials, a 3-factor, 3-level Box-Behnken design was employed to study the effect of cholesterol, soya lecithin, and Span 60 independent variable on dependent variables (particle size and \% entrapment efficiency). Transmission electron microscopy analysis of optimized formulation has demonstrated the presence of individual proniosomes in spherical shape.

Results: Atorvastatin optimized proniosomal formulation F2 shown better particle size and \% entrapment efficiency, and also, the drug release was 99.72\% within $24 \mathrm{~h}$ in slow and controlled manner when compared with control. Kinetic analysis of drug release profiles showed that the drug release was followed by zero-order manner with Korsmeyer-Peppas model, which implies super case II release kinetics. The particle size and zeta potential of the optimized atorvastatin proniosomal gel were found to be 65.72 and -10.5 , respectively. The optimized batch of proniosomes was used for the preparation of atorvastatin-based proniosomal hydrogel by incorporating hydrated proniosomes to carbopol matrix to enhance the stability and viscosity of the system.

Conclusion: The enhanced skin permeation, for a prolonged period of time, may lead to improved efficacy and better patient compliance. This study suggests that proniosomal gel-containing atorvastatin could perform therapeutically better effects than the conventional formulations.

Keywords: Atorvastatin, Proniosomes, Box-Behnken Design, Span 60, Zeta potential.

(c) 2019 The Authors. Published by Innovare Academic Sciences Pvt Ltd. This is an open access article under the CC BY license (http://creativecommons. org/licenses/by/4. 0/) DOI: http://dx.doi.org/10.22159/ajpcr.2019.v12i4.26707

\section{INTRODUCTION}

Drug delivery systems using colloidal particulate carriers such as liposomes or niosomes have distinct advantages over conventional dosage forms because the particles can act as drug-containing reservoirs [1]. The use of non-ionic surfactant vesicles (niosomes) as drug carrier systems has distinct advantages over conventional dosage [2]. They can increase the drug efficacy, reduce drug side effects, increase the drug solubility, and develop an effective topical delivery [3]. Transdermal drug delivery system is among the most widely employed system to overcome the issues associated with oral route, increases the therapeutic efficacy of many drugs by preventing their conversion to undesirable metabolites, and also helps in maintaining uniform plasma levels in vivo [4]. Due to which, it exhibits a high level of patient compliance with low levels of intra- and inter-patient variability [5]. Among various strategies, vesicular systems such as niosomes exhibit substantial potential to overcome such barrier [6,7]. Proniosomal gel when applied to skin under occlusive conditions get hydrated with the skin moisture and converted to niosomes [8]. The additional convenience of the transportation, distribution, storage, and dosing would make "dry niosomes" a promising industrial product. These dry niosomes are hydrated immediately before use and thus avoids some of the problems $[9,10]$ Atorvastatin calcium is a 5-hydroxy-3methylglutaryl-coenzyme A reductase inhibitor used in the treatment of hyperlipidemia [11]. It has an oral bioavailability of $<12 \%$. It also undergoes high first-pass metabolism. It is highly soluble in acidic $\mathrm{pH}$ and absorbed more in the upper part of the gastrointestinal tract [12].

In the present study, the coacervation-phase separation method was used for the preparation and optimization of atorvastatin proniosomes, from a technical viewpoint, and allowed a wider scope to be used to study the influence of various formulation variables. To enhance the stability and viscosity of the system, the proniosomes were mixed with carbopol gel [13].

\section{MATERIALS AND METHODS}

\section{Materials}

Atorvastatin calcium was received as a gift sample from Aurobindo Pharma Ltd., Hyderabad. Span 60 and soya lecithin were purchased from SD Fine Chemicals (Mumbai, India). Cholesterol 95\% stabilized was purchased from Acros Organics. Carbopol P 934 was obtained from MSN Laboratories, Hyderabad. Dialysis tubing was purchased from HiMedia Laboratories (Mumbai, India). All other chemicals and solvents were of analytical grade and were used without further purification.

\section{Methodology}

Drug-excipient compatibility study

Fourier-transform infrared (FTIR) studies

The drug-excipient compatibility studies were performed to check the interaction between drug and excipients. The FTIR spectra of drug sample and its physical mixture with excipients were carried out by potassium bromide disc method using Shimadzu IRAffinity 1 Spectrophotometer in the region of $4000-400 \mathrm{~cm}^{-1}$.

Differential scanning calorimetry (DSC) studies DSC of drug sample and its physical mixture with excipients was carried out using a Perkin Elmer DSC-7 Differential Scanning Calorimeter (PerkinElmer, CT, USA) equipped with a TAC 7/DX Instrument Controller. Analyses were performed in triplicate on $5 \mathrm{mg}$ samples under nitrogen purge. 
Design of experiments

Initially, preliminary experiments (one factor at a time approach) were performed to determine the main factors and the appropriate ranges in which the optima lie. Among all the non-ionic surfactants, Span 60 was selected based on the results of the preliminary experiments. Further, the effect of three factors (concentrations of surfactant, cholesterol, and soya lecithin) on the particle size and \% entrapment efficiency was tested. Through preliminary screening, the concentrations of surfactant, cholesterol, and soya lecithin were identified as the most significant variables within the range of $100-300 \mathrm{mg}, 10-50 \mathrm{mg}$, and 50-200 mg, respectively.

On the basis of the preliminary trials, a 3-factor, 3-level Box-Behnken design was employed to study the effect of each independent variable on dependent variables (particle size and \% entrapment efficiency). The independent factors and the dependent variables used in the design are listed in Table 1. The experiments were conducted on the basis of the design, and the obtained responses for the dependent variables are given in Table 2. The response surfaces of the variables inside the experimental domain were analyzed using Stat-Ease Design-Expert ${ }^{\circledR}$ software V8.0.1. Subsequently, three additional confirmation experiments were conducted to verify the validity of the statistical experimental strategies.

Preparation of proniosomes

Atorvastatin proniosomes were prepared by coacervation-phase separation method [14]. The non-ionic surfactant, cholesterol, and soya lecithin were taken in an appropriate amount as shown in Table 2. All the components were taken in a wide mouth glass tube and dissolved in ether. The drug, atorvastatin $10 \mathrm{mg}$ was dissolved in ethanol (2.5 ml). After mixing all ingredients, the open end of the glass vial was covered with a lid to prevent loss of solvent, and the glass vial warmed in a water bath at $65 \pm 3^{\circ} \mathrm{C}$ to dissolve all the ingredients. The aqueous phase $(0.1 \%$ glycerol solution) was added and warmed in a water bath until a clear solution is formed which, on cooling, converted into a proniosomal gel. The gel obtained was preserved in the same glass tubes in the dark for characterization. The proniosomal structure was a liquid crystalline-compact proniosomal hybrid that was converted into proniosomes on hydration. The system was hydrated by $10 \mathrm{ml}$ of phosphate buffer (pH 7.4) under sonication (Ultrasonic Bath Sonicator, Make - Frontline Electronics, Model - FS-2) at $37^{\circ} \mathrm{C}$.

\section{Characterization of proniosomal gel}

Surface morphology

Surface morphology of proniosomal gel was performed using optical microscopy. A drop of dispersion was taken on a glass slide without a cover slip, and the process of proniosomal formation was observed through an optical microscope (Labomed) and photographs were taken by digital camera $[15,16]$.

\section{Entrapment efficiency}

The entrapment efficiency was determined by separating the unentrapped drug. Proniosomal gel (100 mg) was hydrated with $10 \mathrm{ml}$ of distilled water by manual shaking for $5 \mathrm{~min}$ to form niosomal dispersion. The percentage entrapment efficiency of atorvastatin in hydrated proniosomes was determined by centrifugation technique, which was centrifuged at $14,000 \mathrm{rpm}$, at $4^{\circ} \mathrm{C}$ for $30 \mathrm{~min}$, and the supernatant containing unentrapped drug was withdrawn and analyzed for free drug content by measuring absorbance at $\lambda_{\max } 246 \mathrm{~nm}$ using ultraviolet (UV) spectrophotometer $[17,18]$.

\section{Particle size and size distribution analysis}

For all the batches of proniosomes, particle size analysis was carried out using Malvern Zetasizer Nano ZS (Malvern Instruments, UK).

Table 1: List of dependent and independent variables in Box-Behnken design

\begin{tabular}{|c|c|c|c|c|c|}
\hline \multirow[t]{2}{*}{ Variable } & \multirow[t]{2}{*}{ Name } & \multirow[t]{2}{*}{ Units } & \multicolumn{3}{|l|}{ Levels } \\
\hline & & & Low & Middle & High \\
\hline \multicolumn{6}{|l|}{ Independent variables } \\
\hline A & Concentration of surfactant (Span 60) & $\mathrm{mg}$ & 100 & 200 & 300 \\
\hline $\mathrm{B}$ & Concentration of cholesterol & $\mathrm{mg}$ & 10 & 30 & 50 \\
\hline $\mathrm{C}$ & Concentration of soya lecithin & $\mathrm{mg}$ & 50 & 125 & 200 \\
\hline Dependent variable & & & Goal & & \\
\hline Y1 & Particle size & $\mathrm{nm}$ & Minimize & & \\
\hline Y2 & Entrapment efficiency & $\%$ & Maximize & & \\
\hline
\end{tabular}

Table 2: Box-Behnken experimental design and observed responses

\begin{tabular}{|c|c|c|c|c|c|}
\hline Run & $\begin{array}{l}\text { Factor A Concentration } \\
\text { of surfactant (Span 60) }\end{array}$ & $\begin{array}{l}\text { Factor B Concentration } \\
\text { of cholesterol }\end{array}$ & $\begin{array}{l}\text { Factor C Concentration } \\
\text { of soya lecithin }\end{array}$ & $\begin{array}{l}\text { Response Y1 } \\
\text { Particle size }\end{array}$ & $\begin{array}{l}\text { Response Y2 } \\
\text { Entrapment efficiency }\end{array}$ \\
\hline 1 & 200 & 30 & 125 & 73.21 & 93.23 \\
\hline 2 & 100 & 30 & 50 & 64.68 & 76.12 \\
\hline 3 & 200 & 50 & 200 & 156.72 & 64.32 \\
\hline 4 & 200 & 30 & 125 & 72.48 & 93.82 \\
\hline 5 & 300 & 30 & 200 & 182.18 & 79.34 \\
\hline 6 & 300 & 30 & 50 & 161.72 & 81.12 \\
\hline 8 & 100 & 10 & 125 & 67.12 & 92.34 \\
\hline 9 & 200 & 10 & 200 & 198.12 & 91.82 \\
\hline 10 & 300 & 50 & 125 & 178.1 & 62.18 \\
\hline 11 & 100 & 50 & 125 & 86.1 & 56.1 \\
\hline 12 & 100 & 30 & 200 & 97.46 & 69.17 \\
\hline 13 & 200 & 30 & 125 & 73.46 & 93.12 \\
\hline 14 & 200 & 30 & 125 & 72.69 & 92.86 \\
\hline 15 & 200 & 50 & 50 & 102.56 & 59.72 \\
\hline 17 & 200 & 10 & 50 & 88.72 & 91.74 \\
\hline
\end{tabular}

*Each formulation containing atorvastatin calcium $10 \mathrm{mg}$ 
Scanning electron microscopy (SEM)

SEM was applied to assess the shape and surface morphology of microspheres (HITACHI, S-3700N) [19].

Transmission electron microscopy (TEM) analysis of proniosomes

The morphology of the prepared proniosomes was observed under TEM (JEM-2000 EXII; JEOL, Tokyo, Japan). One drop of diluted atorvastatin pronosomal suspension was deposited on a filmcoated copper grid and stained with one drop of $2 \%(\mathrm{w} / \mathrm{v})$ aqueous solution of phosphotungstic acid and then allowed to dry for contrast enhancement. The samples were examined at the magnification of $72000 \times$ by TEM [20].

\section{In vitro drug release studies}

In vitro release studies of hydrated atorvastatin proniosomal dispersions were done using lab-made static Franz glass diffusion cells. The dialysis membrane was hydrated in the receptor medium, which consisted of a phosphate buffer $\mathrm{pH}$ 6.8, for $24 \mathrm{~h}$ before mounting into a Franz diffusion cell. A $2.5 \mathrm{ml}$ hydrated atorvastatin proniosomal dispersion was placed in the donor chamber and the receptor chamber was filled with $7.5 \mathrm{ml}$ receptor medium and stirred continuously at $100 \mathrm{rpm}$ at $37^{\circ} \mathrm{C}$, and the samples were withdrawn at different time intervals for $24 \mathrm{~h}$ from the receptor chamber through a side-arm tube. After each withdrawal of sample, an equal volume of receptor medium was added to the receptor chamber to maintain a constant volume throughout the study. The samples were analyzed for atorvastatin concentration using UV spectrophotometry at $\lambda_{\max } 244 \mathrm{~nm}$, and measurements were carried out in triplicate [21,22].

\section{Drug release kinetics}

To elucidate the mode and mechanism of drug release, the data from the in vitro release study were fitted into various kinetic models, such as zero-order, first-order, Higuchi's, and Korsmeyer-Peppas model [23].

\section{Stability studies}

The stability study was performed according to the ICH guidelines. The proniosomal gel formulations were filled in tightly closed glass vials and subjected to stability testing. The formulations were kept at refrigerated conditions $\left(4 \pm 1^{\circ} \mathrm{C}\right)$ and room temperature $\left(25 \pm 2^{\circ} \mathrm{C}\right)$ and were analyzed for particle size and entrapment efficiency after 3 months [24].

\section{Formulation of atorvastatin-based proniosomal hydrogel}

Based on the characterization and the particle size, highest entrapment efficiency and high \% of drug release, F2 was selected. The selected F2 hydrated proniosomal formulation was formulated into hydrogel by adding 1\% (w/w) Carbopol P 934 under magnetic stirring at 800rpm. Stirring was continued until carbopol was dispersed. The dispersions were neutralized using triethanolamine solution [25].

\section{Viscosity measurements}

The flow behavior and viscosity of the tested formulations were determined using LV III rotating Brookfield Viscometer using Spindle RV-3 (Brookfield Engineering Laboratories Inc., Stoughton, MA, USA).

\section{Ex vivo permeation study}

Ex vivo permeation study was carried out using male Wistar rat skin as reported by Ibrahim et al. [26]. The rat skin was mounted between the donor and receptor compartment with the stratum corneum facing the upper side on the Franz diffusion cell and phosphate buffer pH 6.8 was taken in receptor compartment. The temperature was maintained at $37 \pm 1^{\circ} \mathrm{C}$. Proniosomal formulation equivalent to $10 \mathrm{mg}$ of atorvastatin was spreaded over the rat skin. The receptor compartment content was stirred with the help of magnetic beads. The samples were collected at different time intervals and were immediately replaced with the fresh media. The samples were analyzed for drug content using UV spectrophotometer at $244 \mathrm{~nm}$. The cumulative amount of drug permeated (Q) at different time intervals and various parameters such asss steady-state flux (Jss), permeability coefficient (Kp), and enhancement ratio were studied.

\section{Skin irritation study of proniosomal hydrogel}

About $0.5 \mathrm{~g}$ proniosomal gel was applied to three rats on an area of skin approximately 1 " $\times 1$ " $(2.54 \times 2.54 \mathrm{~cm})$ square. Animals were returned to their cages. After a $24 \mathrm{~h}$ exposure, the proniosomal gel was removed. The test sites were wiped with tap water to remove any remaining test article residue [27].

\section{Data analysis}

Data were expressed as the mean \pm standard deviation of the mean, and a statistical analysis was carried out by employing the one-way analysis of variance (ANOVA). A value of $\mathrm{p}<0.05$ was considered to be statistically significant.

\section{RESULTS AND DISCUSSION}

\section{Preparation of atorvastatin proniosomes}

In this study, the proniosomes of atorvastatin were formulated, optimized, and evaluated for its efficacy in transdermal drug delivery to overcome the major issues associated with its oral delivery.

\section{Drug-excipient compatibility study}

\section{FTIR studies}

The FTIR spectra of pure atorvastatin calcium (Fig. 1) showed characteristic peaks at $1381 \mathrm{~cm}^{-1}$ (C-N-stretching), $2965.15 \mathrm{~cm}^{-1}$ (C-H-stretching), $1315.56 \mathrm{~cm}^{-1}$ (C-HO-stretching alcoholic group), $1564.97 \mathrm{~cm}^{-1}$ (C=0-stretching amidic group), $3403.27 \mathrm{~cm}^{-1}(\mathrm{~N}-\mathrm{H}-$ stretching), $1775.97 \mathrm{~cm}^{-1}$ (C=C-bending), $751.62 \mathrm{~cm}^{-1} 696.95 \mathrm{~cm}^{-1}$ (C-Fstretching), and $1104.39 \mathrm{~cm}^{-1}$ (O-H-bending). The FTIR spectra of the physical mixture were having similar fundamental peaks and pattern when compared with the pure drug. Thus, there are no significant interactions among the drug and excipients.

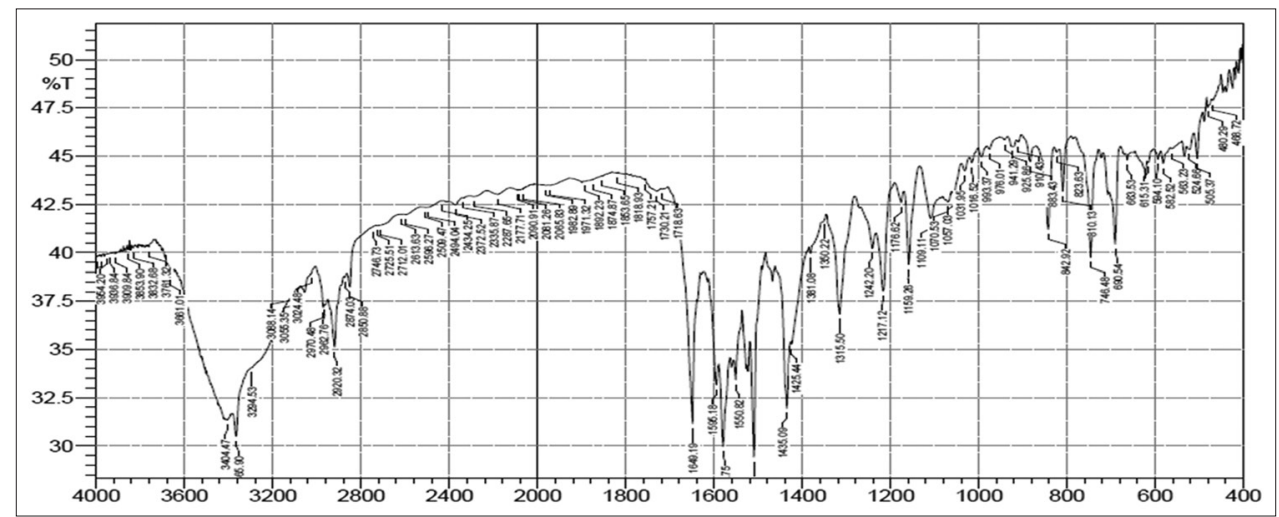

Fig. 1: Fourier-transform infrared spectrum of atorvastatin pure drug 


\section{DSC studies}

DSC thermogram of atorvastatin calcium (Fig. 2) was presented in crystal structure exhibiting sharp melting peaks at 159.7. The DSC thermogram endothermic peak of atorvastatin calcium (Fig. 3) was disappeared in atorvastatin calcium-loaded proniosomes, which ensures that the drug is completely encapsulated and homogeneously dispersed in the proniosomes. The absence of atorvastatin peak on this thermogram has been taken to represent the only evidence of atorvastatin amorphization. The physical state of the drug inside the carrier system is important because it can affect the in vitro and in vivo drug release. The amorphous atorvastatin may be favorable due to the enhanced solubility of the active agent.

\section{Optimization of formulation variables}

Through preliminary experiments, the concentration of surfactant (a), concentration of cholesterol (b), and concentration of soya lecithin (c) were identified as the most significant variables influence the particle size and entrapment efficiency. The formulations were further optimized by considering the parameters such as smaller particle size and maximum entrapment efficiency.

Seventeen experiments were required for the response surface methodology based on the Box-Behnken design. Based on the experimental design, the factor combinations yielded different responses as presented in Table 2 . These results clearly specify that the dependent variables are strongly dependent on the selected independent variables as they show a wide variation among all the 17 batches. Data were analyzed using Stat-Ease Design-Expert ${ }^{\circledR}$ software V8.0.1 to obtain ANOVA, regression coefficients, and regression equation. Mathematical relationships were generated using multiple linear regression analysis for the mentioned variables as shown in Table 3. These equations represent the quantitative effect of concentration of surfactant (a), concentration of cholesterol (b), and concentration of soya lecithin (c) and their interaction on particle size (Y1) and entrapment efficiency (Y2). The values of the coefficients of $A, B$, and $C$ are related to the effect of these variables on the responses Y1 and Y2 (Tables 3 and 4), and coefficients with more than one-factor term and those with higher order terms represent interaction terms and quadratic relationship, respectively. A positive sign represents synergistic effect, while a negative sign indicates antagonistic effect. A backward elimination procedure was adopted to fit the data to the quadratic model. Both the polynomial equations were found to be statistically significant ( $\mathrm{p} \backslash 0.01)$, as determined using ANOVA as per the provisions of Design-Expert software.

The mathematical model generated for particle size (Y1) was found to be significant with F-value of 21.03, implying that the model is significant. There is only a $0.01 \%$ chance that a "model F-value" could occur due to noise $(p<0.0001)$ and $R 2$ value of 0.9424 . The independent variables such as $\mathrm{A}, \mathrm{B}$, and $\mathrm{C}$ and the quadratic term of $\mathrm{BC}, \mathrm{A}^{2}, \mathrm{~B}^{2}$, and $\mathrm{C}^{2}$ have significant effects on the particle size since $\mathrm{p}<0.0001$ represents the significant model terms. Results of the equation indicate that the effect of $\mathrm{A}$ is more significant than B and C. The influence of the main and interactive effects

Table 3: Regression equations for the responses - Particle size and entrapment efficiency

\begin{tabular}{ll}
\hline Response & Regression equation \\
\hline Y1 & $72.99+45.60 \mathrm{~A}+1.43 \mathrm{~B}+27.10 \mathrm{C}-13.81 \mathrm{BC}$ \\
& $+19.67 \mathrm{~A}^{2}+29.69 \mathrm{~B}^{2}+33.84 \mathrm{C}^{2}$ \\
$\mathrm{Y} 2$ & $93.30+3.13 \mathrm{~A}-16.21 \mathrm{~B}-0.51 \mathrm{C}-8.54 \mathrm{~A}^{2}-8.08$ \\
& $\mathrm{~B}^{2}-8.32 \mathrm{C}^{2}$ \\
\hline
\end{tabular}

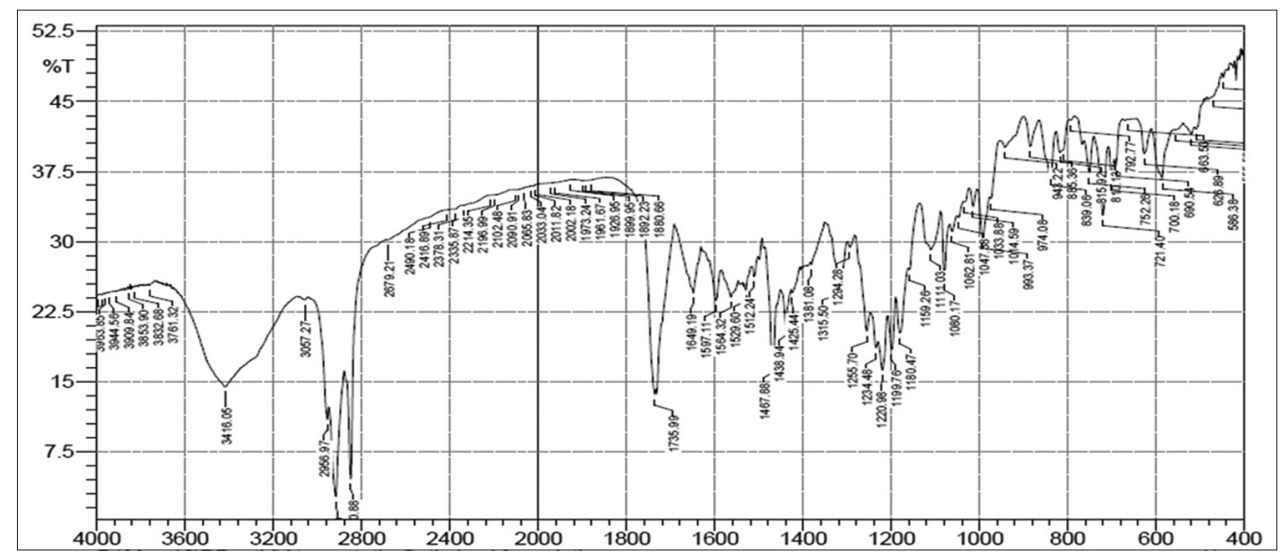

Fig. 2: Fourier-transform infrared spectrum of atorvastatin physical mixture

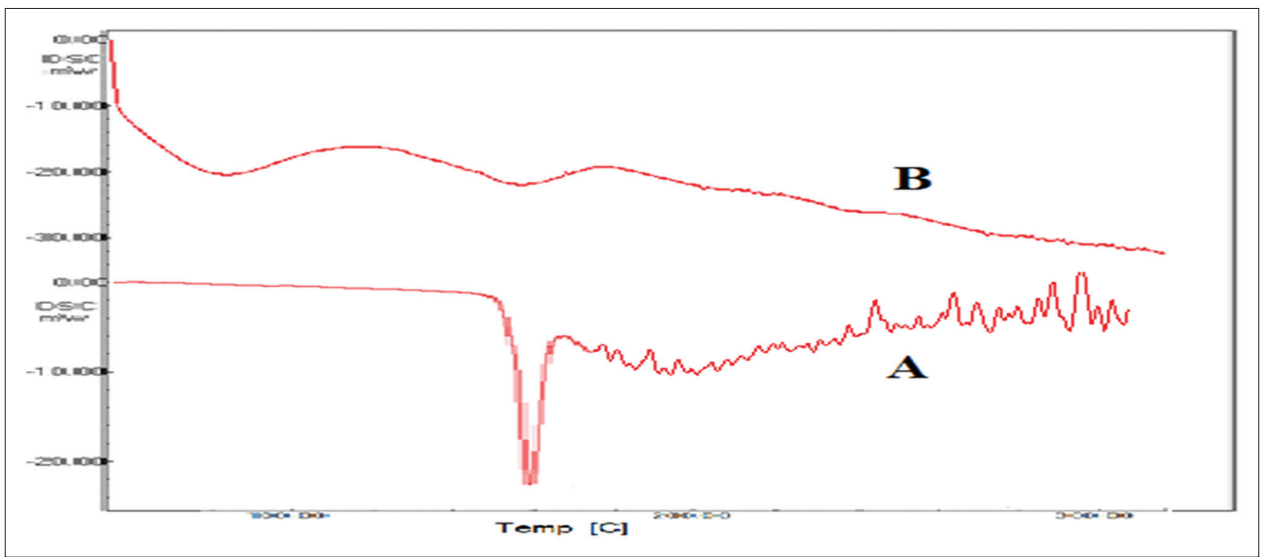

Fig. 3: Differential scanning calorimetry thermograms of (A) pure atorvastatin calcium and (B) atorvastatin physical mixture 
of independent variables on the particle size was further elucidated using the perturbation and three-dimensional (3D) response surface plots. The perturbation plot (Fig. 4) shows the main effects of A, B, and $\mathrm{C}$ on the particle size (Y1). This figure clearly shows that $\mathrm{A}$ has the main and major effect on $\mathrm{Y} 1$, followed by $\mathrm{C}$ which has a moderate effect on $\mathrm{Y} 1$, followed by B which has a little effect on Y1. The relationship between the dependent and independent variables was further elucidated using 3D response surface plots. Fig. 5 shows the interactive effect of $B$ and $C$ on the particle size (Y1) at a fixed level of C. At low levels of A (concentration of surfactant), Y1 increases from $64.68 \mathrm{~nm}$ to $97.46 \mathrm{~nm}$. Similarly, at high levels of A, Y1 increases from $158.12 \mathrm{~nm}$ to $182.18 \mathrm{~nm}$.

Entrapment efficiency of proniosomes was found to be in the range of $56.1-96.12 \%$ as shown in Table 2.

The polynomial equation for entrapment efficiency exhibited a good correlation coefficient (0.9832) and the model F-value of 97.77 implies that the model is significant. There is only a $0.01 \%$ chance that a "model F-value" could occur due to noise. Values of "Prob $>F$ " $<0.0005$ indicate that model terms are significant. In this case A, B and C are the quadratic term of A2, B2 and C2 are significant model terms. Results of the equation indicate that the effect of $B$ (concentration of cholesterol) is more significant than A and C. Two variables $B$ and $C$ have the negative effect on the entrapment efficiency, which means that these factors are inversely proportional to the response, whereas A has a positive effect on entrapment efficiency. The influence of the main and interactive effects of independent variables on the entrapment efficiency was further elucidated using the perturbation and 3D response surface plots. The individual main effects of $\mathrm{A}, \mathrm{B}$, and $\mathrm{C}$ on entrapment efficiency are shown in Fig. 6. It is found that all the variables are having interactive effects for the response Y2. The 3D response surface plots of the response Y2 are shown in Fig. 6 to depict the interactive effects of independent variables on response Y2; one variable was kept constant, while the other two variables varied in a certain range. The shapes of response surface plots reveal the nature and extent of the interaction between different factors. The interaction between A and B on entrapment efficiency at a fixed level of $C$ is shown in Fig. 7. At low levels of A, Y2 reduced from $92.34 \%$ to
$56.1 \%$. Similarly, at high levels of A, Y2 reduced from $96.12 \%$ to $62.18 \%$. At low levels of B, Y2 reduced from $96.12 \%$ to $91.74 \%$. Similarly, at high levels of B, Y2 reduced from $64.32 \%$ to $56.1 \%$. At low levels of C, Y2 reduced from $91.74 \%$ to $59.72 \%$. Similarly, at high levels of C, Y2 reduced from $91.82 \%$ to $64.32 \%$.

A numerical optimization technique using the desirability approach was employed to prepare atorvastatin proniosomes with the desired responses. Constraints such as minimizing the particle size in addition to maximizing the entrapment efficiency were set as goals to locate the optimum settings of independent variables. To verify these values, three batches of proniosomes were prepared according to the predicted levels of A, B, and C. The predicted and observed values are shown in Table 4. Obtained Y1 and Y2 values were in a close agreement with the predicted values. This demonstrated the reliability of the optimization procedure in predicting the operating parameters for the preparation of atorvastatin proniosomes. All the three batches of obtained atorvastatin proniosomes were subjected to further characterization.

The particle size of diluted proniosomes is shown in Table 5, and it ranges from $64.78 \pm 3.43 \mathrm{~nm}$ to $68.12 \pm 4.12$ (Fig. 8) $\mathrm{nm}$ with unimodal particle size distribution, which favors transdermal delivery of atorvastatin. Since the smaller particle size is advantageous to decrease the irritation and improve the penetration of particles into the skin easily. All the proniosomal formulations were negatively charged, which was due to the negative charge present on the soya lecithin. The zeta potential values were high in all the formulations (Table 5 and Fig. 9). The high zeta potential increases the repulsion between the particles and thus prevents their aggregation and flocculation. Hence, it electrically stabilizes the system.

\section{Surface morphology}

Atorvastatin-loaded proniosomal gel formulation prepared using an optimum ratio of lecithin and cholesterol (9:1) demonstrated lamellar structures under a compound microscope (Fig. 10). Hydration of this gel with saline solution leads to swelling of bilayers as well as particles due

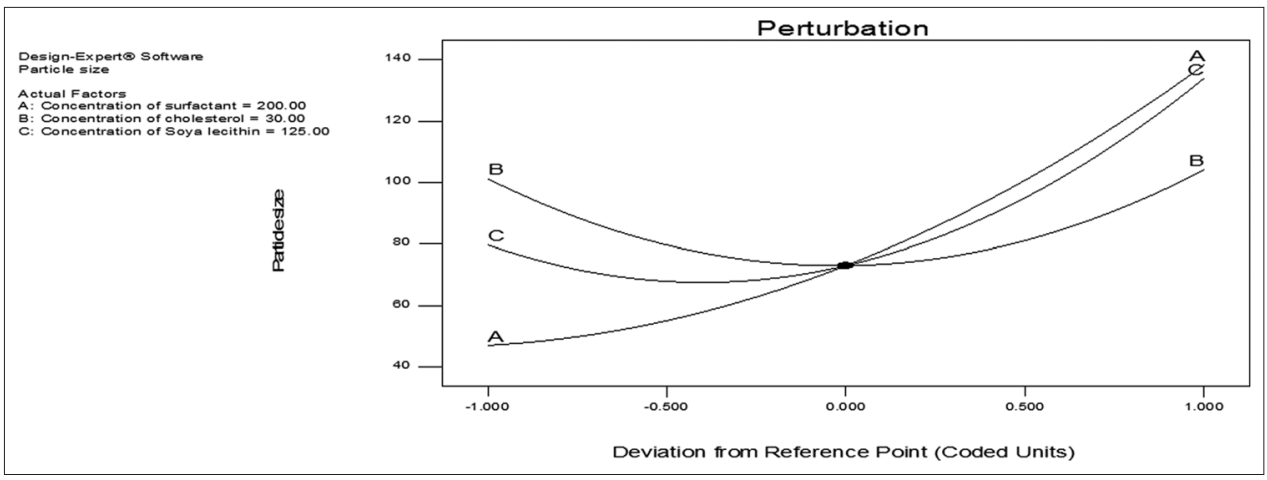

Fig. 4: Perturbation plot showing the effect of $A, B$, and $C$ on particle size

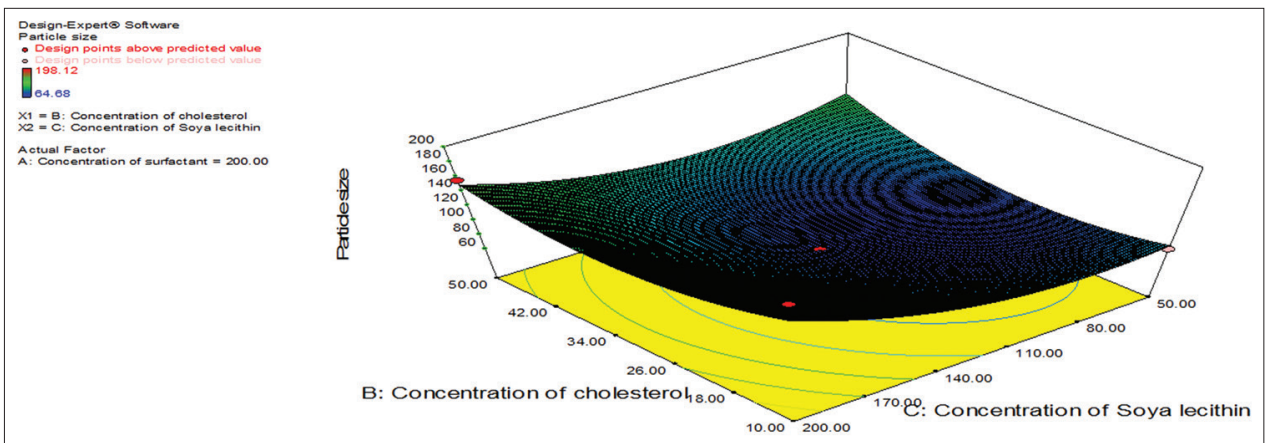

Fig. 5: Response surface plot showing the influence of the concentration of cholesterol and concentration of soya lecithin on particle size 


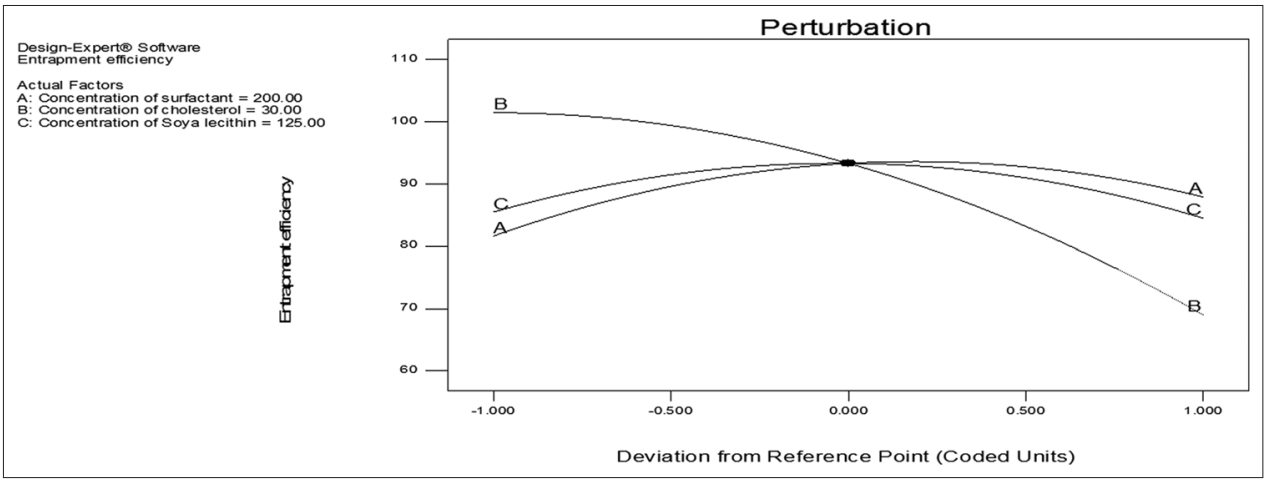

Fig. 6: Perturbation plot showing the effect of A, B, and C on entrapment efficiency optimization and confirmation experiments

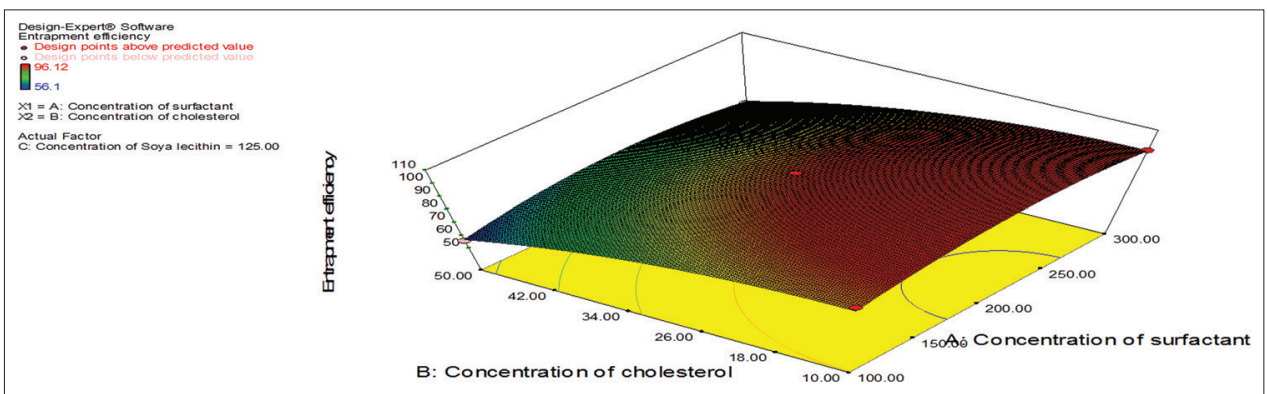

Fig. 7: Response surface plots showing the interactions between the concentration of surfactant and concentration of cholesterol on entrapment efficiency

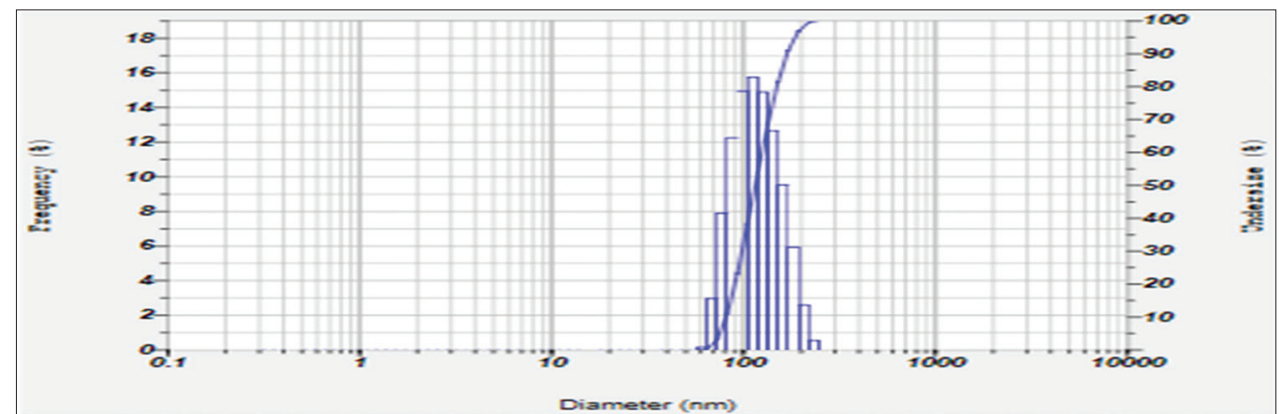

Fig. 8: A graphical representation of particle size of atorvastatin optimized formulation

to the interaction of water with polar groups of surfactants. The bilayer tends to form spherical structure randomly giving rise to multilamellar, multivesicular structures. When shaken with aqueous phase, complete hydration takes place leading to the formation of proniosomes. Observation under an optical microscope revealed that proniosomal gel was progressively but rapidly converted to proniosomes almost completely within minutes.

\section{Scanning electron microscope (SEM) for atorvastatin proniosomes}

SEM studies of optimized formulation of atorvastain proniosomes revealed oval-shaped globules. The size is within nanometers. There are clear liquid droplets without any pores (Fig. 11).

\section{TEM analysis}

TEM analysis has demonstrated the presence of individual proniosomes in spherical shape. The images in Fig. 12 confirmed the proniosomal formation. TEM results were also compatible with atorvastatin particle size measurements.

\section{Drug release study}

From Fig. 13, it is clear that the cumulative release of drug from control was higher than from the proniosomes. This was because atorvastatin was sufficiently lipophilic and it partitions in favor of the proniosomes, which resulted in the slower release in a controlled manner of atorvastatin from proniosomes.

\section{Release kinetics}

Release data for optimized proniosomal formulation were fitted into various kinetic equations to find the order and mechanism of drug release. Kinetic analysis of drug release profiles showed that the systems predominantly released atorvastatin in a zero-order manner with a strong correlation coefficient $\left(\mathrm{R}^{2}=0.9994\right)$ (Fig. 14). The optimized formulation of first-order plot and Higuchi plot is shown in Figs. 15 and 16, respectively. This was corroborated by Korsmeyer-Peppas $\mathrm{n}=0.9053$ ( $\mathrm{n}>0.89$ ) (Fig. 17) which implies super case II release kinetics (a strong indication of zero order). Zero-order release is the ideal in controlled drug release and has been reported not to be common with matrix systems; this is being attributed to time-dependant changes in drug-depleted matrix surface area and diffusional path length. Zero- 


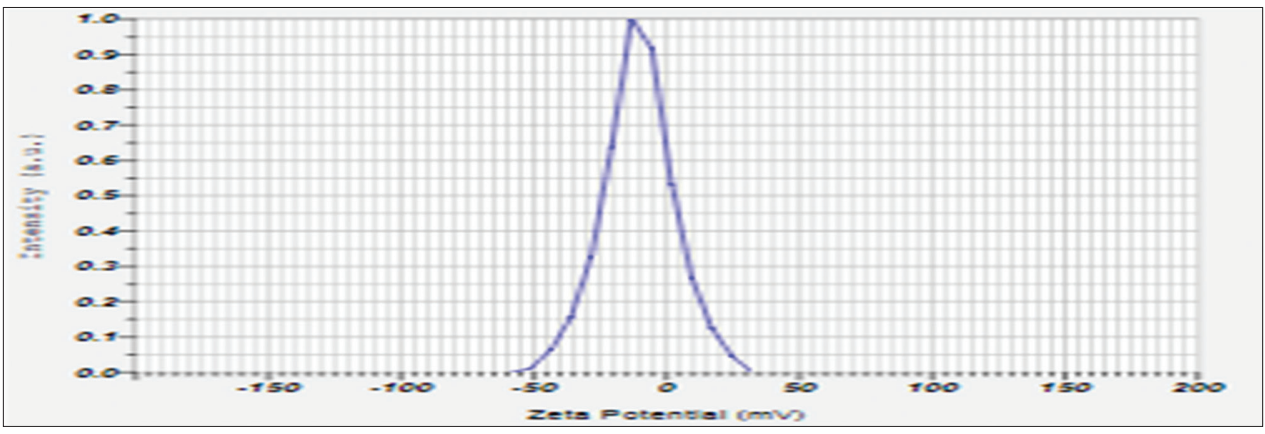

Fig. 9: A graphical representation of zeta potential of atorvastatin optimized formulation
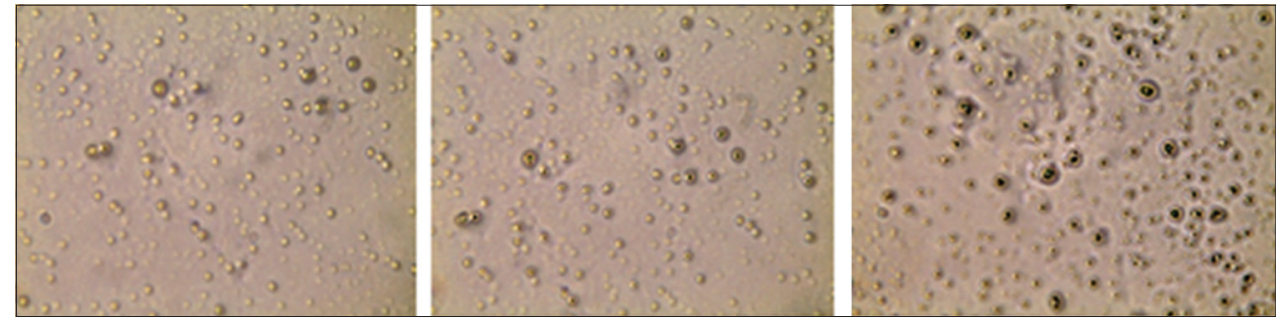

Fig. 10: Optical microscopy images of proniosomes formed on hydration of proniosomal gel at $\times 1000$ magnification
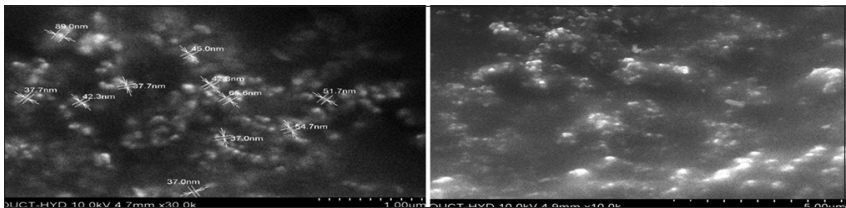

Fig. 11: Scanning electron microscopy photographs of atorvastatin proniosomes

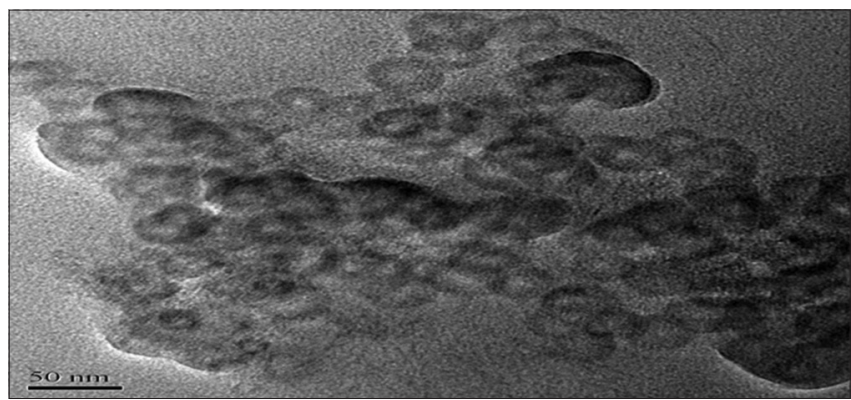

Fig. 12: Transmission electron microscopy image of atorvastatin optimized proniosomes

order release has a lot of advantages including ability to deliver drug at a constant rate, thus providing a predictable bioavailability status. The results are summarized in Table 6 .

\section{Stability study}

From stability studies, it indicates that no significant difference $(\mathrm{p}<0.05)$ was found in entrapment efficiency, particle size, and drug release data of optimized formulation stored at refrigerated conditions and room temperature.

\section{Formulation of atorvastatin-based proniosomal hydrogel}

Atorvastatin proniosomal hydrogel was prepared using Carbopol $\mathrm{P}$ 934. An optimized batch of proniosomes was used for the preparation of atorvastatin-based proniosomal hydrogel by incorporating hydrated proniosomes to carbopol matrix. It is well known fact that the proniosomes get hydrated by skin moisture to form proniosomes,

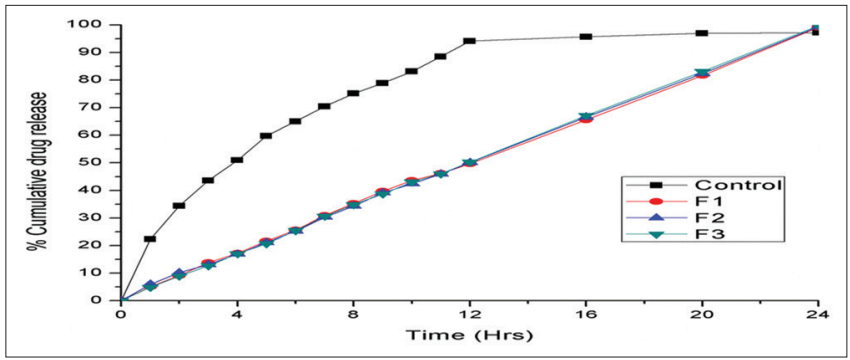

Fig. 13: In vitro release of atorvastatin from proniosomes

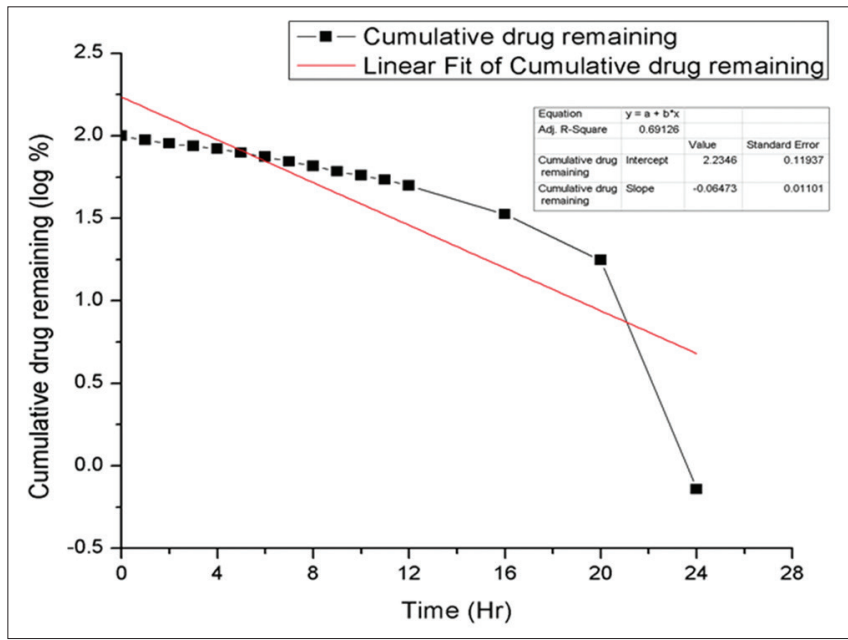

Fig. 14: Plot of zero-order release kinetics of the optimized batch

which have the ability to alter the transportation of drug across the skin. Adsorption and fusion of pronisome onto the skin surface would facilitate the permeation of drug, and barrier properties of stratum corneum are modified because non-ionic surfactant acts as penetration enhancers as it causes the disruption of tightly packed lipids that are filled in the extracellular spaces of stratum corneum. The $\mathrm{pH}$ of the final carbopol hydrogel formulation was found to be 7.18 , hence the need 
Table 4: Optimized values obtained by the constraints applied on Y1 and Y2

\begin{tabular}{|c|c|c|c|c|c|c|}
\hline \multirow[t]{2}{*}{ Independent variable } & \multirow{2}{*}{$\begin{array}{l}\text { Nominal } \\
\text { values }\end{array}$} & \multicolumn{2}{|c|}{ Predicted values } & \multicolumn{3}{|c|}{ Observed values } \\
\hline & & $\begin{array}{l}\text { Particle } \\
\text { size (Y1) }\end{array}$ & $\begin{array}{l}\text { Entrapment } \\
\text { efficiency (Y2) }\end{array}$ & Batch & $\begin{array}{l}\text { Particle } \\
\text { size (Y1) }\end{array}$ & $\begin{array}{l}\text { Entrapment } \\
\text { efficiency (Y2) }\end{array}$ \\
\hline Concentration of surfactant (A) & 166.20 & 63.2398 & 97.74 & $\begin{array}{l}\text { F1 } \\
\text { F2 }\end{array}$ & $\begin{array}{l}66.12 \\
65.72\end{array}$ & $\begin{array}{l}96.34 \\
97.42\end{array}$ \\
\hline Concentration of cholesterol (B) & 17.46 & & & F3 & 65.12 & 97.13 \\
\hline Concentration of soya lecithin (C) & 103.94 & & & & & \\
\hline
\end{tabular}

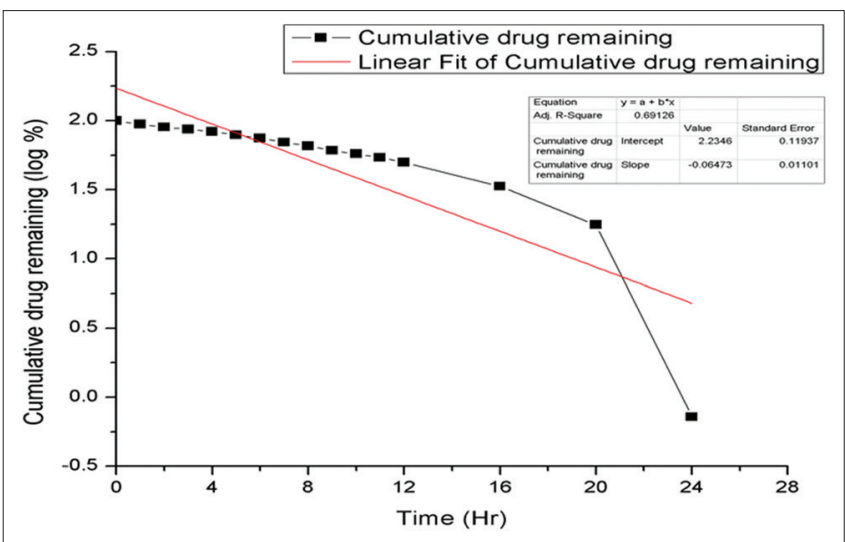

Fig. 15: Plot of first-order release kinetics of the optimized batch

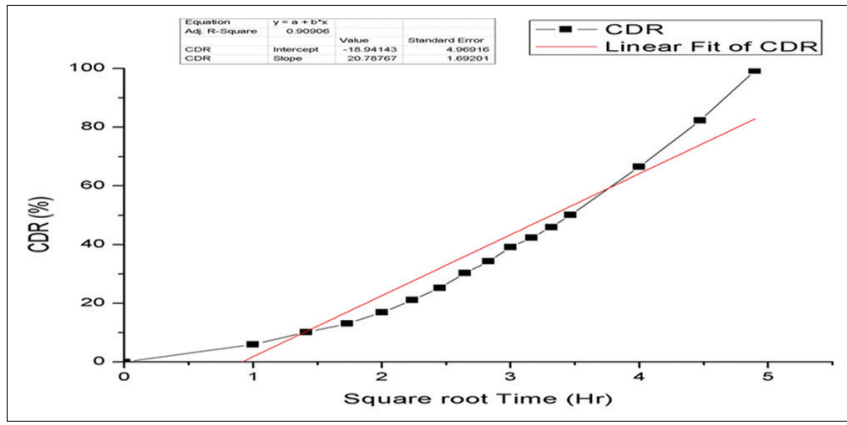

Fig. 16: Plot of Higuchi release kinetics of the optimized batch

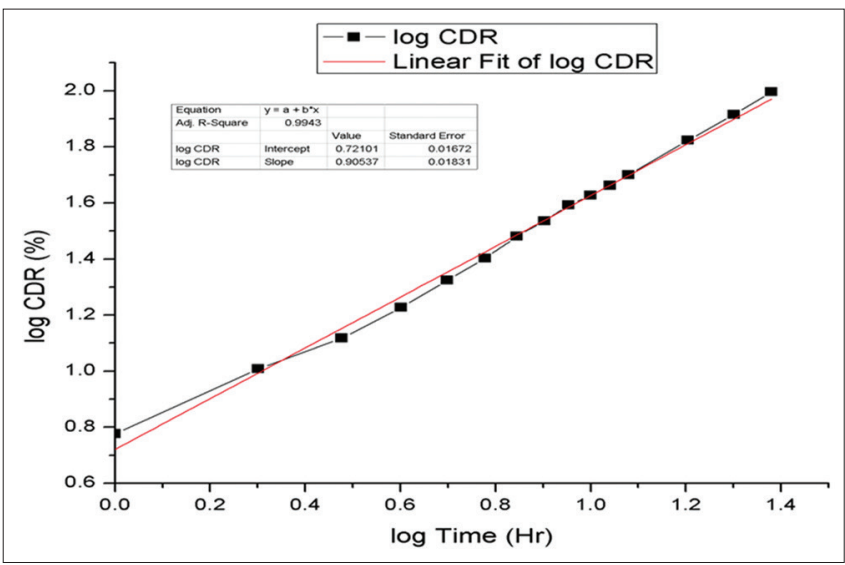

Fig. 17: Plot of Korsmeyer-Peppas release kinetics of the optimized batch

to buffer the formulation with triethanolamine to a $\mathrm{pH}$ of 5.5. The viscosity of the final formulation was found to be $1590.66 \mathrm{cps}$ which is within the acceptable limit.
Table 5: The mean particle size, PDI, entrapment efficiency, and zeta potential of optimized formulations

\begin{tabular}{lllll}
\hline Batch & MVS \pm SD $(\mathbf{n m})$ & PDI & ZP \pm SD $(\mathbf{m V})$ & \% EE \pm SD \\
\hline 1 & $66.12 \pm 1.62$ & 0.712 & $-11.8 \pm 0.73$ & $96.34 \pm 0.18$ \\
2 & $65.72 \pm 2.12$ & 0.605 & $-10.5 \pm 0.18$ & $97.42 \pm 0.37$ \\
3 & $65.12 \pm 1.13$ & 0.782 & $-13.5 \pm 0.82$ & $97.13 \pm 0.82$ \\
\hline \multicolumn{2}{r}{$\mathrm{n}=3(\mathrm{p}<0.05)}$. & SD: Standard deviation, PDI: Poly dispersibility index
\end{tabular}

Table 6: Release kinetics of optimized atorvastatin proniosomes

\begin{tabular}{llllll}
\hline $\begin{array}{l}\text { Formulation } \\
\text { Code }\end{array}$ & $\begin{array}{l}\text { Zero } \\
\text { order }\end{array}$ & $\begin{array}{l}\text { First } \\
\text { order }\end{array}$ & Higuchi & Korsmeyer-Peppas \\
\cline { 2 - 6 } & $\mathbf{R}^{2}$ & $\mathbf{R}^{2}$ & $\mathbf{R}^{2}$ & $\mathbf{R}^{2}$ & $\mathbf{n}$ \\
\hline F2 & 0.99945 & 0.69126 & 0.9090 & 0.9943 & 0.9053 \\
\hline
\end{tabular}

Table 7: Flux of atorvastatin from proniosomes

\begin{tabular}{lll}
\hline Formulation & \multicolumn{2}{l}{ Flux $\left(\mu \mathbf{g ~ c m}^{-2} \mathbf{h}^{-1}\right)$} \\
\cline { 2 - 3 } & Egg membrane & Rat skin \\
\hline F2 & $43.231 \pm 2.68$ & $193.754 \pm 3.126$ \\
Control & $312.115 \pm 2.37$ & $55.635 \pm 5.12$ \\
\hline
\end{tabular}

The release rate (flux) of atorvastatin across the membrane and excised skin differs significantly (Table 7), which indicates about the barrier properties of skin. Interaction between skin and proniosomal component may justify these differences. Association and fusion of proniosomes to the skin surface resulted in higher flux due to the direct transfer of drug from the particles.

\section{Skin irritation studies}

The irritation studies were conducted with animal ethical committee approval bearing No:02/IAEC/VIPER/Ph.D/2017-18, on male Wistar rats $(n=3)$. Formalin was applied as standard irritant. The rats were scored for erythema and edema scale [21,22]. The incidences of erythema and edema were significantly lower $(0.18 \pm 0.112$; $p<0.05)$ in proniosomal formulation-treated rats than those treated with standard irritant, formalin. Hence, it was concluded that the formulations were non-irritant and safe.

\section{CONCLUSION}

This work has demonstrated the use of a 3-factor, 3-level Box-Behnken design, regression analysis, and contour plots in optimizing the formulation variables in the preparation of atorvastatin proniosomes by coacervation-phase separation method. Atorvastatin optimized proniosomal formulation F2 shown better drug release of $99.28 \%$ within $24 \mathrm{~h}$ in slow and controlled manner when compared with control. TEM analysis of optimized formulation has demonstrated the presence of individual proniosomes in spherical shape. Kinetic analysis of drug release profiles showed that the systems predominantly released atorvastatin in a zero-order manner with a strong correlation coefficient $\left(R^{2}=0.9994\right)$. This was corroborated by Korsmeyer-Peppas $n=0.9053$ 
$(\mathrm{n}>0.89)$ which implies super case II release kinetics (a strong indication of zero order). The particle size and zeta potential of the optimized atorvastatin proniosomal gel were found to be $65.72 \mathrm{~nm}$ and -10.5 $\mathrm{mV}$, respectively. Zero-order release has a lot of advantages including ability to deliver drug at a constant rate, thus providing a predictable bioavailability status. An optimized batch of proniosomes was used for the preparation of atorvastatin-based proniosomal hydrogel by incorporating hydrated proniosomes to carbopol matrix to enhance the stability and viscosity of the system. The enhanced skin permeation, for a prolonged period of time, may lead to improved efficacy and better patient compliance than the conventional formulations.

\section{AUTHORS' CONTRIBUTION}

All the authors have equal contribution.

\section{CONFLICTS OF INTEREST}

No conflicts of interest were raised by the authors.

\section{REFERENCES}

1. Singh S, Trivedi S, Jain S. Design and development of proniosome based transdermal delivery of ondansetron hydrochloride. Int J Pharm Biol Res 2012;3:191-201.

2. Schreier H, Bouwstra J. Liposomes and niosomes as topical drug carriers: Dermal and transdermal drug delivery. J Control Release 1994;30:1-15.

3. Aggarwal D, Kaur IP. Improved pharmacodynamics of timolol maleate from a mucoadhesive niosomal ophthalmic drug delivery system. Int $\mathbf{J}$ Pharm 2005;290:155-9.

4. Wen MM, Farid RM, Kaseem AA. Nano-proniosomes enhancing the transdermal delivery of mefenamic acid. J Liposome Res 2014;24:280-9.

5. Aggarwal G, Dhawan S. Psychotropic drugs and transdermal delivery: An overview. Int J Pharm Bio Sci 2010;1:1-12.

6. Morrow DI, McCarron PA, Woolfson AD, Donnelly RF. Innovative strategies for enhancing topical and transdermal drug delivery. Open Drug Deliv J 2007;1:36-59.

7. Vyas SP, Khar RK. Targeted and Controlled Drug Delivery-Novel Carrier Systems. $1^{\text {st }}$ ed. India: CBS Publishers and Distributors; 2004. p. 249-79.

8. Kaushik D, Mishra PR, Talegaonkar S. Provesicles as surrogate carrier for improved drug delivery. In: Jain NK, editor. Progress in Controlled and Novel Drug Delivery System. India: CBS Publishers and Distributors; 2004. p. 59-274.

9. Alia B, Elnabarawi MA, Elrehem RT, Fayed BA. Formulation and evaluation of dispersed permethrin proniosomes in powder and microemulsion-based hydrogel bases for the treatment of scabies. Int $\mathrm{J}$ Pharm Sci 2016;8:221-9.

10. Aacharya A, Kumar GB, Ahmed MG, Paudel S. A novel approach to increase the bioavailability of candesartan cilexetil by proniosomal gel formulation: In-vitro and In-vivo evaluation. Int J Pharm Sci 2016;8:241-6

11. Florey K. Analytical Profiles of Drug Substances. New York: Academic
Press, Inc.;2004. p. 577.

12. Bullen WW, Miller RA, Hayes RN. Development and validation of a high- performance liquid chromatography tandem mass spectrometry assay for atorvastatin, ortho-hydroxy atorvastatin, and para-hydroxy atorvastatin in human, dog, and rat plasma. J Am Soc Mass Spectrom 1999;10:55-66.

13. Pankaj S, Rini T, Dandagi PM. Formulation and evaluation of proniosome based drug delivery system of antifungal drug clotrimazole. Int J Pharm Sci Nanotech 2013;8:1945-5.

14. Vora B, Khopade AJ, Jain NK. Proniosomes based transdermal delivery of levonorgestrel for effective contraception. J Control Release 1998:54:149-65.

15. Thakur R, Anwer MK, Shams M, Ali A, Khar R.K, Shakeel F, et al. Proniosomal transdermal therapeutic system of losartan potassium: Development and pharmacokinetic evaluation. J Drug Target 2009;17:442-9.

16. Yousuf M, Ahmad M, Usman M, Ketotifen I. Fumarate and salbutamol sulphate combined transdermal patch formulations: In vitro release and ex vivo permeation studies Ali. Ind J Pharm Sci 2013;75:569-77.

17. Rahman SA, Abdelmalak NS, Badawi A, Elbayoumy T, Sabry N, El Ramly A. Formulation of tretinoin-loaded topical proniosomes for treatment of acne: In-vitro characterization, skin irritation test and comparative clinical study. Drug Deliv 2015;22:731-9.

18. Jaafari MR, Bavarsad N, Bazzaz BS. Effect of topical liposomes containing paromomycin sulfate in the course of leishmania major infection in susceptible BALB/Mice anti-microbial agents and chemotherapy. Am Soc Microbiol 2009;53:2259-65.

19. Ruan G, Feng SS. Preparation and characterization of poly (lactic acid)poly (ethylene Glycol)-poly lactic acid (PLA-PEG-PLA) microspheres for the controlled release of paclitaxel. Biomaterials 2003;24:5307-44.

20. Rahman SA, Abdelmalak NS, Badawi A, Elbayoumy T, Sabry N, El Ramly A. Formulation of tretinoin-loaded topical proniosomes for treatment of acne: In-vitro characterization, skin irritation test and comparative clinical study. Drug Deliv 2015;22:731-9.

21. El-Maghraby GM, Ahmed AA, Osman MA. Penetration enhancers in proniosomes as a new strategy for enhanced transdermal drug delivery. Saudi Pharm J 2015;23:67-74.

22. Balch DA, Cooke RA. A study of the composition of hen's egg shell membranes. Ann Biol Anim Biochim Biophys 1970;10:13-25.

23. Yasam VR, Jakki SL, Natarajan J, Kuppusamy G. A review on novel vesicular drug delivery: Proniosomes. Drug Deliv 2014;21:243-9.

24. Akhtar M, Imam SS, Ahmad MA, Najmi AK, Mujeeb M, Aqil M. Neuroprotective study of Nigella sativa-loaded oral provesicular lipid formulation: In-vitro and ex-vivo study. Drug Deliv 2014;21: 487-94.

25. Rahman SA, Abdelmalak NS, Badawi A, Elbayoumy T, Sabry N, El Ramly A. Formulation of tretinoin-loaded topical proniosomes for treatment of acne: In-vitro characterization, skin irritation test and comparative clinical study. Drug Deliv 2015;22:731-9.

26. Ibrahim MM, Sammour OA, Hammad MA, Megrab NA. In-vitro evaluation of proniosomes as a drug carrier for flurbiprofen, AAPS PharmSciTech 2008;9:782-90.

27. Draize JH, Woodard G, Calvery HD. Methods for the study of irritation and toxicity of substances applied topically to the skin and mucous membranes. J Pharm Exp Ther 1944;82:377-90 